\title{
El neolítico de la Cueva del Niño (Aýna, Albacete) en el contexto de la Sierra del Segura
}

\author{
The Neolithic of El Niño Cave (Ayna, Albacete) in the \\ Sierra del Segura Context
}

Alejandro García Moreno

MONREPOS Archaeological Research Centre and Museum for Human Behavioural Evolution, RGZM Neuwied, Alemania. Instituto Internacional de Investigaciones Prehistóricas de Cantabria (IIIPC). Universidad de Cantabria garcia@rgzm.de

Miriam Cubas

Instituto Internacional de Investigaciones Prehistóricas de Cantabria (IIIPC), Universidad de Cantabria. Sociedad de Ciencias Aranzadi. San Sebastián/Donosti

mcubas@aranzadi-zientziak.org

\section{Ana Belén Marín-Arroyo}

Instituto Internacional de Investigaciones Prehistóricas de Cantabria (IIIPC). Universidad de Cantabria anabelen.marin@unican.es

\section{Joseba Ríos Garaizar}

Centro Nacional de Investigación sobre Evolución Humana (CNIEH), Burgos joseba.rios@cenieh.es

\section{José Eugenio OrTiz}

Laboratorio de Estratigrafía Biomolecular. Escuela Técnica Superior de Ingenieros de Minas. Universidad Politécnica de Madrid.

joseeugenio.ortiz@upm.es

\section{Trinidad DE ToRRES}

Laboratorio de Estratigrafía Biomolecular. Escuela Técnica Superior de Ingenieros de Minas. Universidad Politécnica de Madrid

trinidad.torres@upm.es

\section{Inés LóPEZ DóRIGA}

Instituto Internacional de Investigaciones Prehistóricas de Cantabria (IIIPC), Universidad de Cantabria. Centro de Investigação em Biodiversidade e Recursos Genéticos (CIBIO), Instituto de Ciências e Tecnologias Agrárias e AgroAlimentares, Universidade do Porto ineslopezlopezdoriga@gmail.com

\section{Ana Polo Díaz}

Departamento de Geografía, Prehistoria y Arqueología. Universidad del País Vasco,Vitoria/Gazteiz anapolodiaz@gmail.com

\section{Aixa San Emeterio Gómez}

Instituto Internacional de Investigaciones Prehistóricas de Cantabria (IIIPC). Universidad de Cantabria aixitaseg@gmail.com

\section{Diego Garate Maidagan}

Arkeologi Museoa, Bilbao garatemaidagandiego@gmail.com 
Recibido: 17-12-2014

Aceptado: 18-02-2015

\title{
RESUMEN
}

Desde su excavación en el verano de 1973, la Cueva del Niño ha sido considerada un yacimiento de gran importancia para conocer el proceso de introducción de la economía de producción o de la tecnología cerámica en el sureste de la Península Ibérica, y especialmente para establecer cómo dicho proceso pudo haber afectado a las poblaciones ya asentadas en la región de la Sierra del Segura. Sin embargo, la información proporcionada por la Cueva del Niño resultaba muy fragmentaria, debido a la falta de un estudio de conjunto de las ocupaciones neolíticas del yacimiento. En este artículo, se presenta el análisis de las producciones cerámicas, la industria lítica y los restos de fauna, así como las dataciones existentes para los niveles holocenos del depósito. La revisión de las diversas evidencias proporcionadas por el yacimiento permite plantear que la Cueva del Niño habría actuado probablemente como una estación para el pastoreo y la caza, sirviendo como satélite de otros yacimientos de mayor entidad. No obstante, las limitaciones impuestas por el hecho de tratarse de una excavación efectuada hace cuarenta años impide aportar aspectos concluyentes sobre la dinámica del proceso de introducción del Neolítico en la Sierra del Segura.

Palabras Clave: Neolitico, interior peninsular, Sierra del Segura, neolitización, Holoceno, economía de producción, pastoreo.

\begin{abstract}
Since its excavation in the summer of 1973, El Niño cave has been considered a key site to understand the process of production economy and pottery technology introduction in South-eastern Iberian Peninsula, and especially to approach how such process could have affected people already settled in the Segura mountains. However, data from El Niño cave was very fragmentary, due to the lack of a broad study of Neolithic occupations of the site. In this paper, we present the analysis of pottery, lithic industry and faunal remains, as well as the existing dates from the site's Holocene levels. The review of different evidence from the site allows suggesting that El Niño cave would have probably acted as a hunting and shepherding station, being a logistical site of larger places. However, limitations due to the fact that we are dealing with a 40-year-old excavation, prevent specifying how the process of Neolithic introduction in the Segura Mountains occurred.
\end{abstract}

Key words: Neolithic, Iberian Peninsula, Segura Mountains, Neolithization, Holocene, Production Economy, Shepherding.

\section{Introducción}

El yacimiento de la Cueva del Niño constituye, por su localización y registro arqueológico, un enclave fundamental en el análisis y comprensión del proceso de adopción de la economía de producción y de diversas innovaciones tecnológicas, como la cerámica, en el interior peninsular.

Por su situación en la cuenca del río Segura, el yacimiento ha sido generalmente considerado un punto clave en el corredor natural de introducción de las prácticas neolíticas desde las áreas del Levante y/o el sur Peninsular (Hernández Pérez 2002). Además también se ha apuntado su importancia en el impacto que este proceso de neolitización habría tenido en las formas de vida y la organización social del sustrato poblacional existente
(Mingo et al. 2012; Rodríguez González 2008). La presencia de pinturas rupestres de estilo Levantino en el abrigo exterior de la cavidad, asociadas al depósito arqueológico, confiere al yacimiento un papel importante en el debate sobre la cronología y autoría del Arte Levantino (García Atiénzar 2011; Mateo Saura 1997-1998).

No obstante, la información proporcionada por la Cueva del Niño resulta fragmentaria, debido a la ausencia de un análisis de conjunto y un estudio sistemático de las ocupaciones neolíticas de la cavidad. Por este motivo se decidió llevar a cabo una revisión del material arqueológico recuperado en la campaña de 1973 y un programa de datación, con el objetivo de conocer las ocupaciones prehistóricas de la cavidad e integrar este yacimiento en el contexto regional del sureste peninsular. 


\section{Descripción del yacimiento arqueológico}

\subsection{Historia de las intervenciones}

El yacimiento fue dado a conocer en 1970, al descubrirse sus pinturas rupestres paleolíticas, publicadas por Almagro Gorbea en 1971 (Almagro Gorbea 1971). En el verano de 1973, una excavación arqueológica dirigida por I. Davidson permitió documentar la existencia de ocupaciones humanas en la cavidad que abarcaban desde el Paleolítico Medio hasta el Neolítico (Higgs et al. 1976). Más tarde, fruto de una remoción descontrolada en el yacimiento, se halló un recipiente cerámico en un excelente estado de conservación, atribuido al Neolítico Antiguo por sus características morfológicas y decorativas (Martí Oliver 1988).

La constatación de la existencia de ocupaciones neolíticas en la cavidad permitió su inclusión en diversos trabajos de síntesis sobre la introducción del Neolítico en la región (Hernández Pérez 2002; Rodríguez González 2008), en los que se apunta la importancia del yacimiento en el proceso de introducción de la economía de producción en el sureste peninsular. Sin embargo, el carácter fragmentario y descontextualizado de la información disponible sobre el yacimiento impedía una correcta valoración de esas ocupaciones neolíticas (García Atiénzar 2011). Debido a esto, a partir de 2010 se decidió comenzar una revisión sistemática del yacimiento, mediante una serie de proyectos encaminados al análisis de los restos líticos, óseos y cerámicos procedentes de la excavación de 1973, así como a la obtención de una batería de dataciones que permitiesen concretar la cronología de las sucesivas ocupaciones de la cavidad.

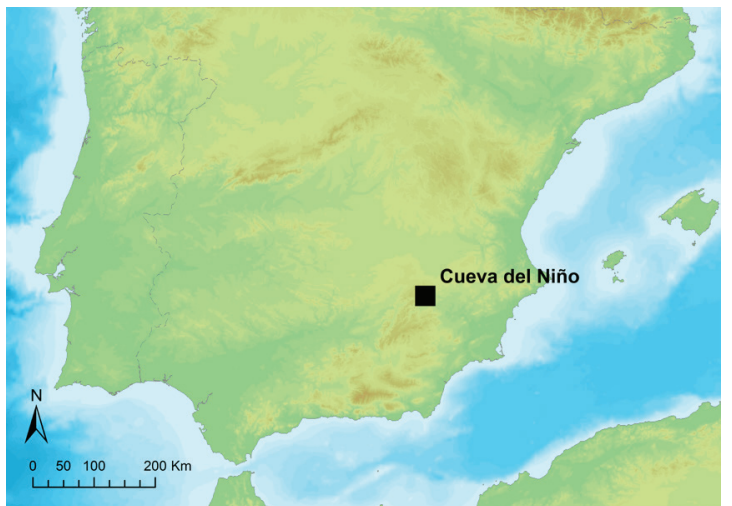

Fig. 1. Localización de la Cueva de Niño (Aýna, Albacete) en el contexto de la Península Ibérica (García Moreno).

\subsection{Localización y descripción del yacimiento}

La Cueva del Niño se localiza en el municipio de Ayna, al sur de la provincia de Albacete, enmarcado geográficamente en la Sierra de Alcaraz, formando parte de la Sierra del Segura que se encuentra en una zona de transición entre la llanura manchega y las Cordilleras Béticas (Fig. 1). Está situado en el cauce medio del río Mundo, principal afluente del río Segura, en un tramo donde éste discurre encajado en un cañón excavado en las calizas del Jurásico. El paisaje en esta zona se caracteriza por un relieve abrupto, en el que destaca la presencia de barrancos como el que acoge a la Cueva del Niño, denominado Barranco del Infierno. No obstante, más allá del cañón del río Mundo, el paisaje se vuelve más ondulado, propio de una penillanura.

El yacimiento arqueológico se encuentra en el abrigo formado por la boca de la Cueva del Niño. Este abrigo, de unos 10 metros de longitud y orientado al este, se abre al pie de una pared vertical, frente a una pequeña terraza que se asoma al barranco. En el extremo suroeste del abrigo se localizan las pinturas rupestres de estilo Levantino. El interior de la cavidad apenas presenta depósito arqueológico, más allá de un pequeño hogar datado en el Paleolítico Superior (Garate Maidagan y García Moreno 2011). Se ha identificado la presencia de un estrato ceniciento que se extiende por gran parte del vestíbulo, de unos 2-5 $\mathrm{cm}$. de potencia, que podría indicar la existencia de un antiguo redil para ganado, aunque, por el momento, la ausencia de un análisis micromorfológico y de macrorrestos vegetales impide confirmar esta hipótesis.

\subsection{Secuencia estratigráfica}

Durante la campaña de 1973 se efectuaron varios sondeos en diferentes zonas del interior (en el vestíbulo) y el exterior (frente a la boca de la cueva y bajo el panel de pinturas Levantinas) de la cavidad (Davidson 1981: Capítulo 10; Davidson y García Moreno 2013) (Fig. 2). La secuencia principal del depósito se definió a partir de dos trincheras realizadas en la entrada, de $2 \times 3$ (Trench 1) y $2 \times 4$ (Trench 2) metros y en las que se alcanzó una profundidad de más de dos metros. En estas dos trincheras se identificaron once niveles arqueológicos, de los que tan sólo los dos superiores (Niveles I y II) corresponden a ocupaciones post-pleistocenas, perteneciendo el nivel III al Paleolítico Medio (García Moreno et 


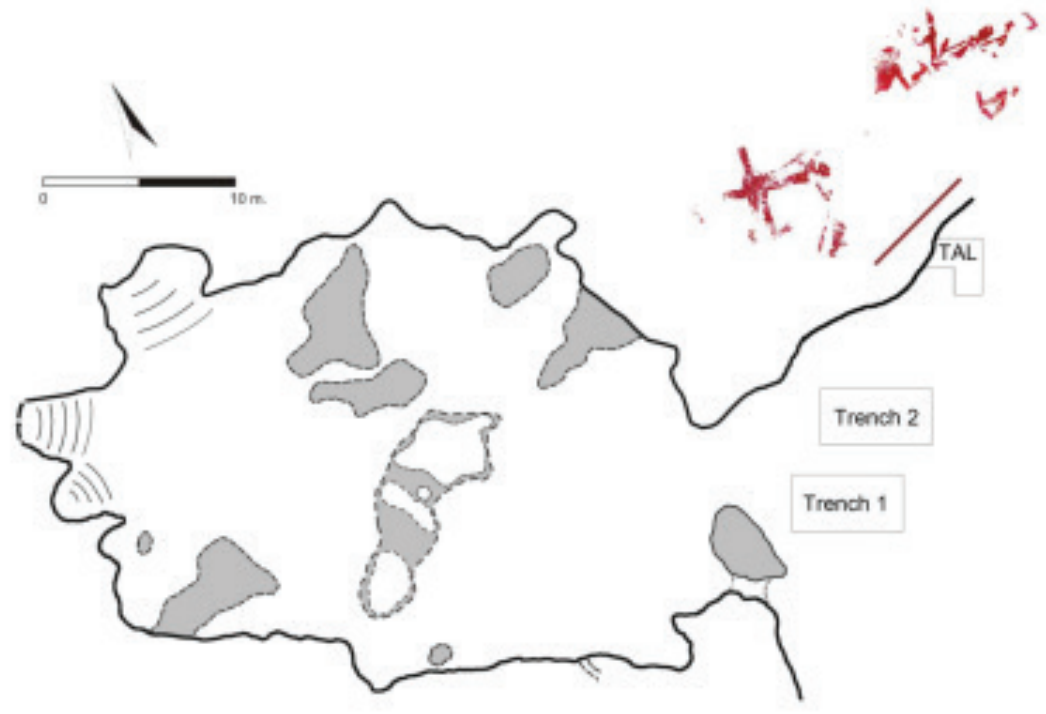

Fig. 2. Planta de la Cueva del Niño donde se indica la posición de los tres sondeos considerados en este trabajo, así como de las pinturas de estilo Levantino (Garate Maidagan y García Moreno, creado a partir de Higgs et al. 1976).

al. 2014). La excavación se realizó siguiendo tramos (spit) artificiales de potencia variable, aunque atendiendo a los cambios en la coloración y textura del sedimento (Davidson 1981: Capítulo 10). Posteriormente estos tramos fueron asociados con los diferentes niveles arqueológicos que componen la secuencia, aunque en algunos de ellos dicha asociación se ha perdido, y resulta por lo tanto imposible adscribir los restos a un nivel concreto.

El Nivel I constituye el estrato superficial, y está formado por un sedimento grisáceo y suelto, que presenta manchas cenicientas. Por su parte, el Nivel II posee unas características sedimentológicas similares al I, aunque en este caso presentaba lentejones de color marrón. En su interior se diferenciaron dos subniveles, denominados IIa y IIb. El material cerámico procedente de las trincheras exteriores, denominadas Trench $1 \mathrm{y}$ Trench 2, corresponde a esta unidad.

No obstante, el Nivel II presenta una serie de problemas que dificultan su interpretación cronológica. En primer lugar, y a pesar de la definición de dos subniveles, no es posible concretar si todo este estrato correspondería al Neolítico o si, por el contrario, incluye también ocupaciones anteriores, como parece sugerir la presencia de materiales arqueológicos de aspecto arcaico, como lascas y núcleos Levallois, un núcleo discoide o un bifaz (García Moreno et al. 2014). De igual modo, las dataciones obtenidas para este nivel resultan problemáticas (ver más abajo), lo que invita a tomar con precaución su análisis. Por el contrario, durante el proceso de excavación no se identificó ningún tipo de alteración que llevase a los excavadores a pensar que este nivel estuviese revuelto, por lo que resulta imposible por el momento, a falta de nuevas excavaciones, valorar con seguridad la integridad del nivel. Sea como fuere, esta posible alteración no es especialmente problemática en el caso de la cerámica, dado su carácter diagnóstico desde un punto de vista cronológico, aunque no sucede lo mismo con la industria lítica o con los restos de fauna, donde resulta más difícil discriminar su cronología en ausencia de un contexto estratigráfico evidente.

Por su parte, en el extremo sureste del abrigo, bajo el panel de pinturas de estilo Levantino, se efectuó un tercer sondeo, denominado Trinchera Arte Levantino (TAL). Este sondeo, de tres metros cuadrados, ofreció una potencia mucho menor que las dos trincheras de la entrada, aunque en este caso pudieron definirse varios niveles correspondientes al Holoceno (Fig. 3):

- Nivel I: Capa superficial que a su vez fue subdividida en dos niveles; el superior, de matriz suelta y grisácea, proporcionó material arqueológico, mientras que el inferior, de color rosáceo, resultó estéril. 
W

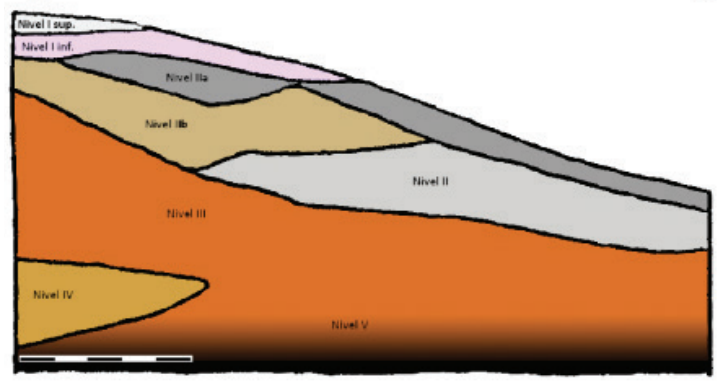

Fig. 3. Perfil Norte del sondeo Trinchera Arte Levantino (TAL) (García Moreno a partir de Davidson 1981: Capítulo 10).

- Nivel II: este estrato también fue subdividido en dos subniveles, el primero de color grisáceo (IIa), y el segundo de coloración, marrón y polvoriento (IIb).

- Nivel III: compuesto por tierra rojiza, con terrones blancuzcos quebradizos, que probablemente correspondiesen a carbonatos.

- Nivel IV: sólo fue identificado en uno de los tres cuadros que formaban este sondeo (E26). Se trata de una capa de arcilla rojiza, que resultó muy pobre en material arqueológico.

- Nivel V: nivel inferior de la secuencia, formado por una mezcla de tierra rojiza y clastos de gran tamaño, correspondientes ya a la roca madre.

Este sondeo resulta el más indicado para el análisis de las ocupaciones neolíticas del yacimiento, ya que toda la secuencia puede asociarse a momentos holocenos, y no presenta la indefinición y falta de integridad que podrían afectar al Nivel II de la secuencia definida en Trench 1 y Trench 2.

\subsection{Estudios previos}

Durante la intervención arqueológica, entre las diversas áreas de excavación se recuperaron un total de 617 piezas líticas, 1963 restos óseos y 122 fragmentos cerámicos, además de documentarse en el vestíbulo de la cavidad algunas estructuras de combustión pertenecientes al Paleolítico Superior (Garate Maidagan y García Moreno 2011). La industria ósea y los restos de fauna fueron estudiados de forma preliminar como parte de la Tesis Doctoral de Davidson (1981: Capítulo 10), mientras que la cerámica fue analizada por Chapman (Apéndice en Davidson 1981: Capítulo 10).

La cerámica recuperada resultó escasa, aunque su carácter diagnóstico permitió una asignación crono-cultural al Neolítico. De acuerdo a la memoria de excavación (Davidson 1981: Capítulo 10), se recogieron 91 fragmentos cerámicos repartidos entre los Niveles I y II de la estratigrafía exterior, 15 de ellos correspondían a fragmentos de bordes, mientras que los 76 restantes a galbos; tan sólo dos restos estaban decorados, uno de ellos con decoración impresa e incisa, y mamelones. Además de éstos, se recogieron en superficie 30 fragmentos más, dos de ellos de tipo campaniforme y con decoraciones impresas paralelas.

Según el análisis de Chapman, la totalidad de fragmentos estaba realizada a mano, con pastas cuya coloración variaba entre tonos anaranjados a grises o marrones oscuros, y que en algunos casos incluían desgrasantes de calcita o cuarzo. La cocción posiblemente se habría realizado en condiciones de oxidación incompleta, dado que las superficies interiores presentaban coloraciones más oscuras o negras, mientras que en algunos fragmentos las superficies exteriores estaban bruñidas. A partir de los elementos decorativos y las características morfológicas, Chapman distinguió dos momentos de ocupación de la cavidad: el Calcolítico, representado por varios fragmentos de cerámica campaniforme; y el Neolítico, representado por el fragmento con decoración incisa e impresa, y que Chapman sitúa en torno al 6000 B.C. por paralelos en el sureste peninsular.

No obstante, el elemento cerámico más característico procedente del yacimiento no fue hallado durante la intervención arqueológica de 1973, sino años más tarde en el transcurso de una intervención irregular. Se trata de un vaso prácticamente completo, de forma globular, que presenta dos asas en cinta y cuya decoración está formada por estrechas franjas de dos líneas paralelas rellenas de cortas incisiones perpendiculares $\mathrm{u}$ oblicuas (Fig. 4), que según Martí Oliver (1988) se encuadraría en el Neolítico Antiguo o Medio peninsular.

Por lo que respecta a la fauna de mamíferos, se recuperaron un total de 1963 restos óseos, 456 procedentes del conjunto de niveles superiores (incluyendo las dos trincheras exteriores y el sondeo bajo el panel de pinturas Levantinas), de los que 125 fueron identificados a nivel taxonómico y anatómico (Davidson y García Moreno 2013). El taxón mejor representado es Oryctolagus cuniculus, cuya presencia en el yacimiento podría ser fruto de factores no antrópicos, como la acción de depredadores, aunque también se ha señalado su importancia en la dieta de las comunidades meso- 


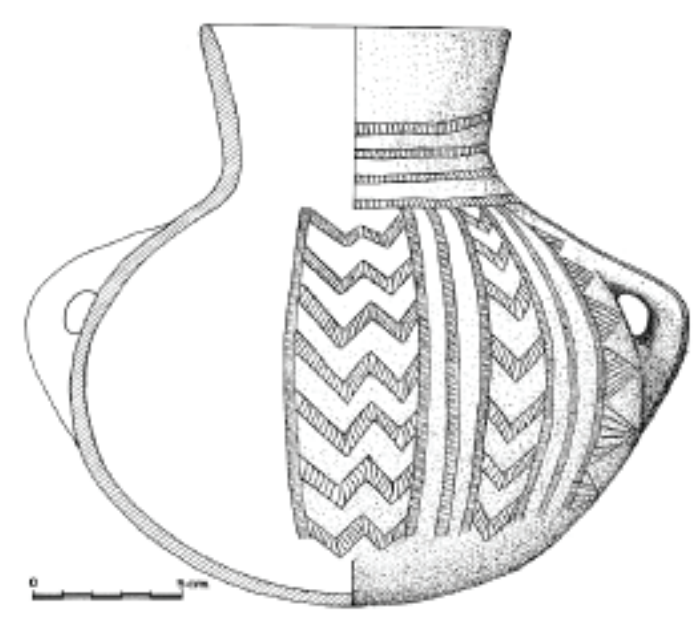

Fig. 4. Vaso forma globular con asas en cinta decoración formada franjas paralelas e incisiones, procedente de una remoción descontrolada del yacimiento (Martí Oliver 1988).

líticas del Levante peninsular (Aura Tortosa et al. 2006). Entre los ungulados, destaca la presencia de cápridos $\mathrm{y}$, en menor medida, de cérvidos.

Finalmente, los Niveles I y II de Trench 1 y Trench 2 proporcionaron un total de 238 restos líticos, mientras que otros 194 fueron recogidos en TAL (Davidson 1981: Capítulo 10; Davidson y García Moreno 2013). El conjunto se caracteriza por un predominio del sílex como materia prima dominante y el elevado índice laminar. Varios de los útiles recuperados apuntaban claramente a una cronología mesolítica o neolítica, como microlitos geométricos, núcleos de laminillas o de talla por presión o productos laminares con tratamiento térmico. Junto a ellos, los útiles más expeditivos realizados en cuarcita fueron interpretados como una posible adaptación local a la materia prima del entorno (Davidson 1986, 1991), ya que durante el proceso de excavación no se distinguió ninguna alteración estratigráfica importante.

No obstante, la falta de un análisis exhaustivo del material arqueológico, así como de dataciones absolutas, impedía concretar la naturaleza de las ocupaciones neolíticas de la cavidad, por lo que se decidió llevar a cabo una revisión pormenorizada del registro arqueológico de El Niño.

\section{Análisis de las manufacturas cerámicas}

El conjunto cerámico de la Cueva del Niño está formado por 122 fragmentos procedentes de las

\begin{tabular}{|l|c|c|}
\hline \multirow{4}{*}{ Sondeo } & Nivel & $\mathbf{N}^{\mathbf{0}}$ de fragmentos \\
\hline \multirow{3}{*}{$\begin{array}{l}\text { Trinchera Arte } \\
\text { Levantino } \\
(\text { TAL })\end{array}$} & Superficial & 20 \\
\cline { 2 - 3 } & 1 & 25 \\
\cline { 2 - 3 } & 3 & 14 \\
\cline { 2 - 3 } & Limpieza perfil & 6 \\
\hline \multirow{3}{*}{ Trench 1 } & 1 & 2 \\
\cline { 2 - 3 } & Sin adscripción & 3 \\
\hline Trench 2 & Superficial & 5 \\
\hline & 1 & 31 \\
\hline & 2 & 1 \\
\hline Trinchera C & & 2 \\
\hline TOTAL & & $\mathbf{1 2 2}$ \\
\hline
\end{tabular}

Tabla 1. Distribución de los restos cerámicos por niveles.

zonas de excavación Trench 1, Trench 2 y TAL (Tabla 1). Esta última es la que presenta un mayor número de efectivos, además de ser la única en la que se observa una clara adscripción de los fragmentos a los tres primeros niveles de la secuencia. De estos 122 restos, un total de 32 no tienen procedencia estratigráfica clara, al haber sido documentados en el nivel superficial o de limpiezas de corte (Tabla 1). Como ya se ha comentado más arriba, los niveles I y II de las trincheras exteriores (Trench 1 y 2) presentan ciertas dudas en cuanto a su integridad estratigráfica, por lo que el análisis de las manufacturas cerámicas se centra fundamentalmente en TAL, haciendo una referencia más somera al material procedente de Trench 1 y Trench 2.

La muestra presenta un elevado índice de fragmentación; los fragmentos de mayor tamaño alcanzan una longitud de $76,11 \mathrm{~mm}$ y una anchura de $75,68 \mathrm{~mm}$, lo que contrasta con la media observada para ambas variables, de $32,23 \pm 13,62$ $\mathrm{mm}$ y $31,16 \pm 14,09 \mathrm{~mm}$ respectivamente. El material cerámico presenta un tamaño similar en las tres áreas de excavación.

El nivel superficial de TAL está compuesto por un total de 20 fragmentos, de los cuales la mayoría corresponden a galbos $(n=13)$; la muestra se completa con tres fragmentos de borde y un asidero (Fig. 5a y 5b) y tres fragmentos de morfología indeterminada. Los bordes presentan una direccionalidad recta o exvasada, mientras que el asidero presenta un desarrollo vertical y 


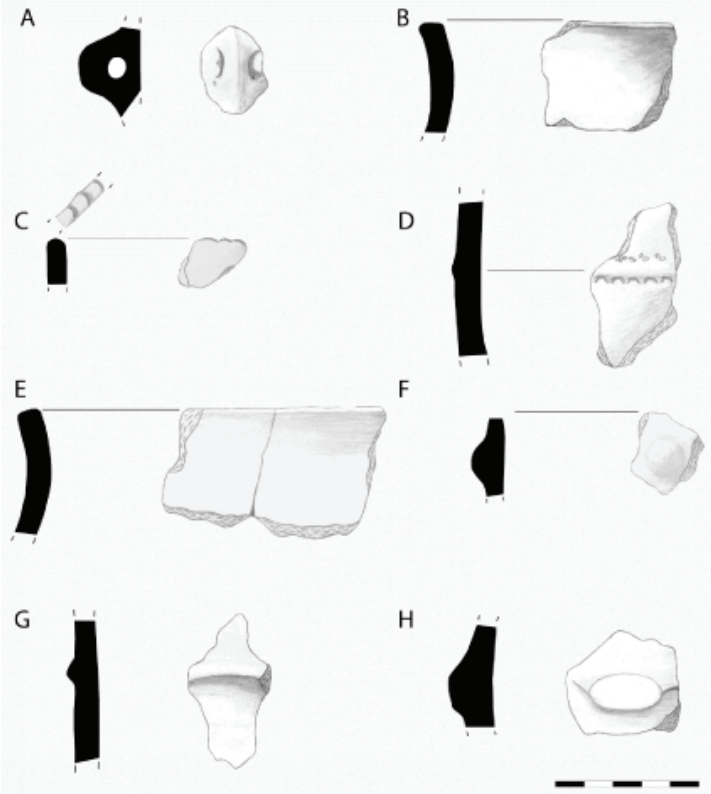

Fig. 5. Morfologías de los fragmentos cerámicos más característicos documentados en la secuencia de la cueva del Niño. A-B. Nivel superficial (TAL). C-D. Nivel I (TAL). E. Nivel II (TAL). F. Nivel III (TAL). G-H. Nivel I (Trench 1) (Cubas).

una perforación horizontal, posiblemente relacionada con la suspensión del recipiente. El número de fragmentos decorados es escaso $(n=4)$ aunque en tres de ellos es muy representativa. Los motivos decorativos se disponen en frisos realizados por incisión o impresión que encierran motivos lineales oblicuos realizados por la impresión de un instrumento múltiple, característico de la cerámica campaniforme (Fig. 6a).

Respecto al nivel I, se trata de un conjunto formado por 25 fragmentos, en su mayor parte galbos y galbos indeterminados, entre los que se documentan cinco bordes. Este conjunto se caracteriza por una elevada porosidad y la existencia de inclusiones de naturaleza mineral, entre las que se ha identificado la calcita que alcanza un tamaño de $3 \mathrm{~mm}$. El grosor medio $\left(n=21^{1}\right)$ es de 7,4 mm con una desviación de 1,49. Su distribución se ajusta a la curva normal ( $\mathrm{S}-\mathrm{W}=$ 0,99 ; $\mathrm{p}$-valor $=0,99$ ) lo que denota una cierta intencionalidad en la obtención de recipientes de este grosor. Las coloraciones reflejan un predominio de la atmósfera alternante $(n=19)$, siendo la oxidante y reductora claramente minoritarias. La mayor parte de los fragmentos presentan sus superficies regularizadas, aunque se han obser-

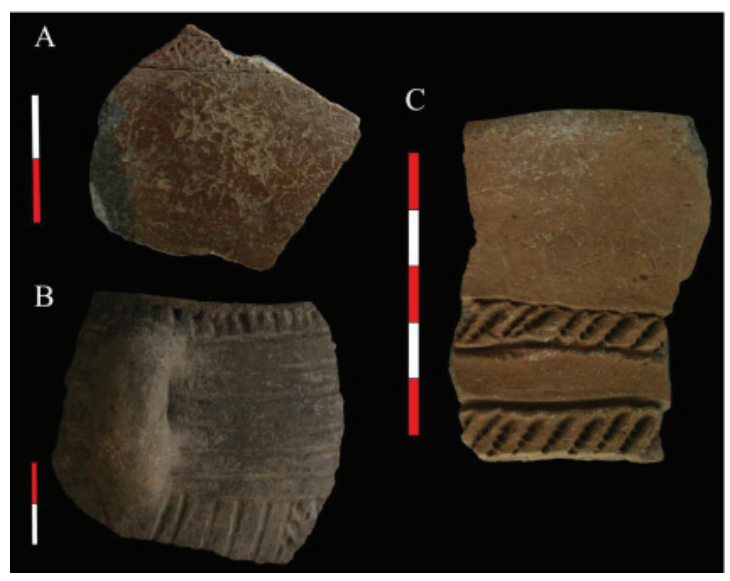

Fig. 6. A. Fragmento campaniforme (Nivel Superficial, TAL). B. Recipiente globular con decoración incisa (Nivel II, TAL). C. Fragmento de vaso campaniforme (Nivel I, Trinchera 2) (Cubas).

vado trazas tecnológicas relacionadas con los tratamientos de alisado, tanto en la superficie exterior $(n=9)$ como interior $(n=6)$, y raspado $(n=2)$. Tres fragmentos han sido decorados mediante ungulaciones o impresiones de matriz o con la adición de cordones horizontales (Fig. 5c y 5d).

El nivel II de TAL está compuesto por 14 fragmentos de elevada porosidad, debido a la densidad de inclusiones minerales no plásticas, como calcita, posiblemente empleada como desgrasante. Las cerámicas se caracterizan por una manufactura a mano y un grosor de $7,9 \pm 1,14$ $\mathrm{mm}$, cuya población se ajusta a una distribución normal $(\mathrm{S}-\mathrm{W}=0,94$; $\mathrm{p}$-valor $=0,48)$. Se han observado trazas tecnológicas relacionadas con el alisado y el raspado en dos casos; éste último aparece en la superficie interior de uno de los fragmentos. Las coloraciones denotan un predominio de la atmósfera alternante y reductora, propia de cocciones al aire libre que no requieren de estructuras constructivas. Al igual que sucedía en el nivel suprayacente, se trata en su mayoría de galbos e indeterminados, habiendo tan sólo cuatro bordes; dos de los bordes remontan entre sí, por lo que pueden individualizarse tres recipientes (Fig. 5e). Únicamente, un fragmento presenta motivos decorativos, si bien son bastante característicos. Se trata de un recipiente de morfología globular, con asidero vertical que presenta una decoración inciso-impresa que cubre la totalidad de la superficie exterior, exceptuando el elemento de prehensión (Fig. 6b). 
Finalmente, el nivel III presenta un conjunto muy escaso $(n=6)$ con predominio de cocción alternante $(\mathrm{n}=4)$ y la utilización de desgrasantes de naturaleza mineral -calcita-, que confiere a los recipientes una elevada porosidad. Dos de los fragmentos son bordes, uno de ellos con un elemento decorativo en forma de mamelón de sección circular (Fig. 5f).

Por lo que respecta a Trench 1, se recuperaron 13 restos procedentes del nivel I, además de tres fragmentos sin adscripción estratigráfica (véase la Tabla 1). El conjunto presenta unas características similares a las cerámicas de TAL, estando caracterizadas por una elevada porosidad, con la utilización mayoritaria de desgrasantes minerales, fundamentalmente calcita, así como un predominio de cocciones alternantes. Se trata en todos los casos de productos elaborados a mano que, en general, presentan superficies regularizadas. Los fragmentos morfológicamente representativos son muy escasos, únicamente dos bordes, uno de ellos con decoración plástica realizada mediante la adhesión de un cordón horizontal en la superficie exterior (Fig. 5 g y $\mathbf{5 h}$ ).

Finalmente, Trench 2 deparó un conjunto de 37 restos cerámicos, aunque sólo seis de ellos presentan adscripción estratigráfica, cinco al nivel superficial y tan sólo uno procedente del nivel II. Es posible por lo tanto que el resto de fragmentos pertenezcan al nivel I, aunque este aspecto es imposible de verificar. Todas las cerámicas de Trench 2 presentan una manufactura a mano y una elevada porosidad debido a la presencia de inclusiones no plásticas de naturaleza mineral. Se observan trazas tecnológicas relacionadas con el tratamiento superficial, en concreto con el alisado, el raspado y el bruñido de las superficies, este último únicamente en la superficie exterior de un fragmento. La mayoría de los fragmentos presentan una cocción alternante. En este conjunto se ha documentado un vaso cuya morfología y decoración son características de los materiales campaniformes. Presenta un borde con direccionalidad exvasada y morfología apuntada convexa y un diámetro aproximado de $100 \mathrm{~mm}$, además de una decoración inciso-impresa típicamente campaniforme, formada por dos frisos paralelos delimitados por dos líneas incisas horizontales, en cuyo interior se disponen una serie de impresiones, con instrumento múltiple, formando líneas oblicuas paralelas (Fig. 6c).

En definitiva, el conjunto cerámico de la Cueva del Niño se caracteriza esencialmente por la manufactura a mano, no habiéndose documen- tado ningún fragmento realizado a torno, y la cocción alternante, así como por el empleo de desgrasantes minerales, fundamentalmente calcitas. Las escasas formas reconocidas indican una posible funcionalidad relacionada con el procesado o almacenaje de alimentos, mientras que la alta fragmentación del conjunto y la ausencia de remontados sugiere que la fragmentación no se produjo in situ y que se trata por lo tanto de un contexto de descarte.

Desde el punto de vista cronológico, a pesar de la gran indefinición formal del conjunto, contamos con varios fragmentos que, por su decoración, permiten una aproximación cronológica al depósito, cuya evolución puede seguirse en TAL. Así pues, en esta zona de excavación, tres fragmentos procedentes del Nivel I presentan una decoración inciso-impresa típicamente campaniforme, mientras que el fragmento decorado del Nivel II se correspondería con una cronología neolítica. En función de las características morfológicas y decorativas de las cerámicas, pueden plantearse dos momentos de ocupación de la cavidad durante el Holoceno: uno en torno a finales del VI e inicios del V milenio cal BC, en el Neolítico, y otro posterior a lo largo del III milenio cal $\mathrm{BC}$, durante el Calcolítico.

\section{Análisis de la industria lítica}

Como ya se comentó más arriba, los niveles superiores de Trench 1 y 2 presentan una serie de problemas que dificultan su interpretación, entre los que se encuentran la presencia de elementos líticos claramente postpaleolíticos, como microlitos geométricos, con otros de aspecto más arcaico, como lascas y núcleos de tipo Levallois. Esto hace que la interpretación cuantitativa del conjunto lítico procedente de estos niveles sea problemática, al no poder diferenciarse qué elementos corresponden realmente a momentos Holocenos y cuáles podrían ser más antiguos. Por otra parte, no fue posible localizar algunos de los útiles dibujados en la memoria de excavación, haciendo imposible su revisión; en estos casos se decidió emplear la clasificación tipológica realizada por Davidson (1981, Capítulo 10). En este trabajo presentamos un análisis preliminar de la industria lítica de los niveles superiores de la secuencia, desde un punto de vista eminentemente cualitativo que permite identificar sus características principales, a la espera de un análisis más detallado que permita solventar las dificultades comentadas. 


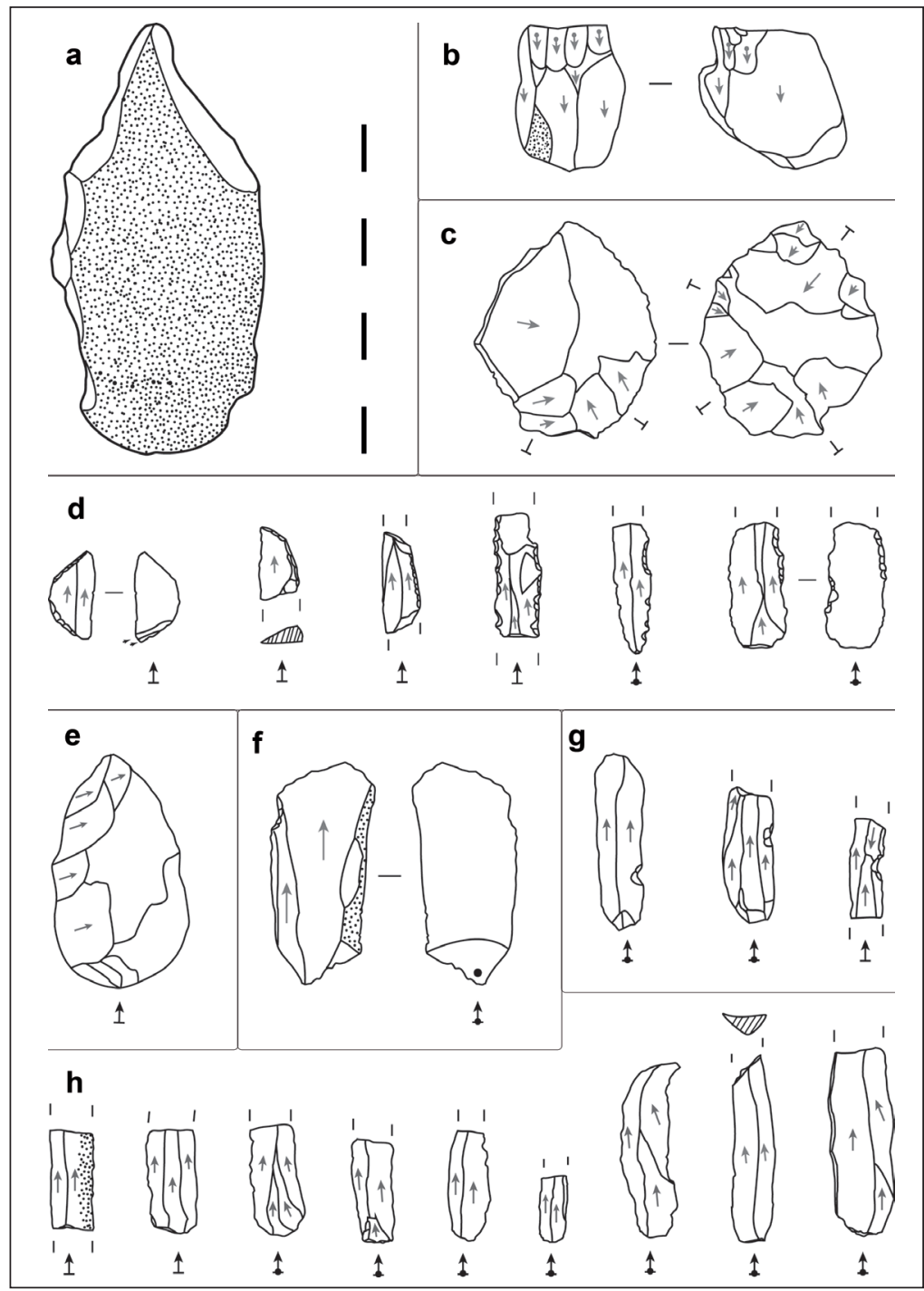

Fig. 7. Industria lítica procedente de los niveles superiores de la Cueva del Niño. Puede apreciarse la presencia tanto de elementos microlaminares y geométricos así como de otros elementos más expeditivos: a) pico de cuarcita; b) núcleo de laminillas; c) núcleo Levallois; d) microlitos geométricos y laminillas retocadas; e) pieza bifacial; f) lámina de cuarcita; g) laminillas con muesca; h) laminillas (San Emeterio Gómez y Rios Garaizar).

El total de elementos líticos procedentes de los niveles superiores de la secuencia estratigráfica, (áreas de excavación Trench 1, Trench 2 y TAL) es de 343 , además de 71 restos de talla no individualizados. Como ya apuntó Davidson en su estudio previo, el conjunto se caracteriza por el dominio del sílex como materia prima empleada para la talla $(\mathrm{n}=223,64,45 \%)$ frente a la cuarcita $(\mathrm{n}=99$, $28,61 \%$ ); otras materias primas empleadas marginalmente son la caliza, el cuarzo o la radiolarita.

Respecto a los soportes, el conjunto presenta un elevado índice laminar (Fig. 7 y 8), con un total de $90(26,01 \%)$ soportes laminares entre láminas, laminillas y fragmentos, además de cinco microlitos geométricos. Esta alta laminaridad se traduce en la presencia de un número significativo $(n=13)$ de núcleos o fragmentos de núcleos de láminas o de laminillas.

Desde un punto de vista tipológico, como ya hemos comentado existen diversos elementos que remiten a la posible presencia de materiales más antiguos mezclados en los niveles superiores, como un núcleo Levallois en sílex (Fig. 7 y 8), un núcleo Quina sobre cuarcita o varias lascas 

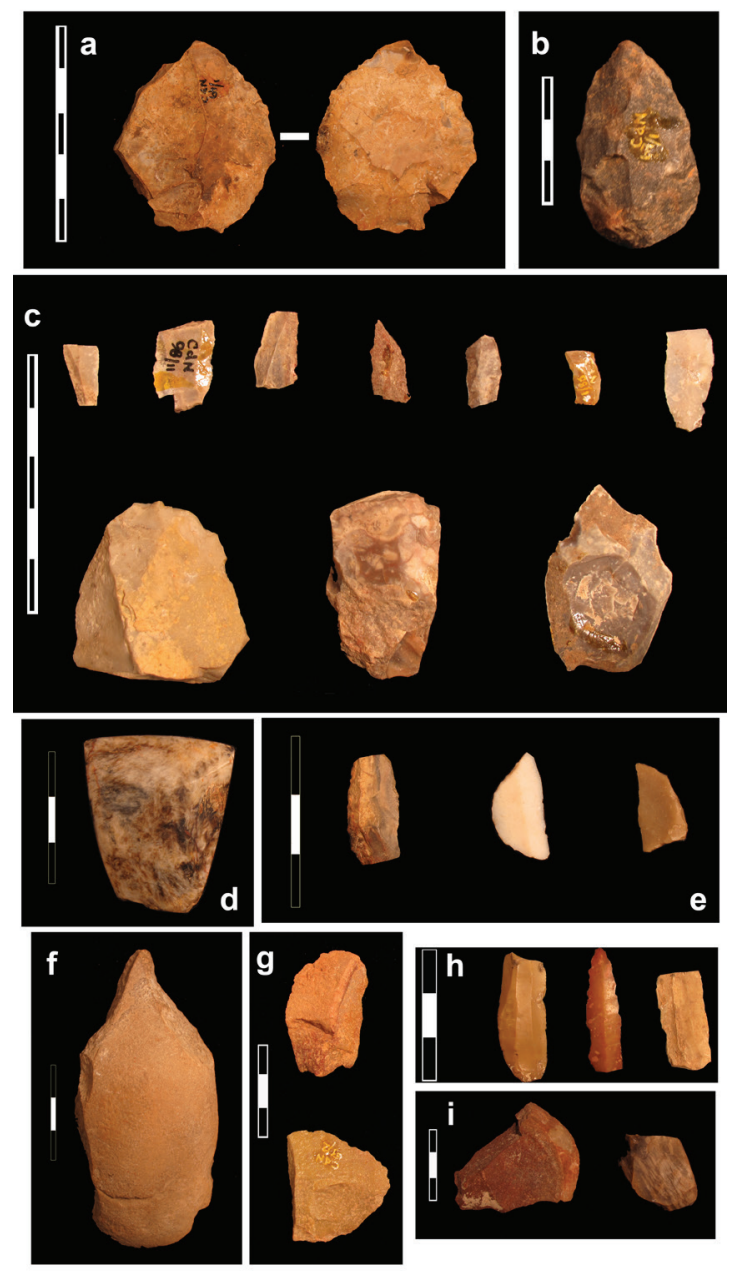

Fig. 8. Industria lítica procedente de los niveles superiores de la Cueva del Niño: a) núcleo Levallois; b) pieza bifacial; c) fragmentos de laminilla junto a materiales más expeditivos, de aspecto arcaico; d) azuela pulimentada; e) microlitos geométricos; f) pico de cuarcita; g) lascas de cuarcita; h) laminillas retocadas; i) chunk de cuarcita y núcleo de laminillas (Rios Garaizar, García Moreno y San Emeterio Gómez).

Levallois. No obstante, la mayoría de útiles presentes remiten claramente a una cronología holocena, destacando especialmente los microlitos geométricos (Fig. 7 y 8), característicos de los conjuntos tanto mesolíticos como del Neolítico Antiguo (Juan-Cabanilles 2008).

También resulta muy diagnóstica una azuela pulimentada (Fig. 8), cuya asignación estratigráfica es dudosa y que, al no aparecer recogida en la memoria de excavación, podría proceder de una recogida superficial posterior. Las azuelas de este

\begin{tabular}{|l|c|c|c|c|}
\hline \multicolumn{1}{|c|}{ Nivel } & Sílex & Cuarcita & Otros & TOTAL \\
\hline$?$ & 125 & 21 & 5 & 151 \\
\hline Upper layers & 87 & 45 & 6 & 138 \\
\hline I & 105 & 43 & 1 & 149 \\
\hline II & 1 & 0 & 0 & 1 \\
\hline IIa & 5 & 3 & 0 & 8 \\
\hline IIb & 37 & 9 & 1 & 47 \\
\hline TOTAL & $\mathbf{3 6 0}$ & $\mathbf{1 2 1}$ & $\mathbf{1 3}$ & $\mathbf{4 9 4}$ \\
\hline
\end{tabular}

Tabla 2. Distribución de los restos líticos por niveles y tipos de materias primas.

tipo son muy comunes en el Neolítico Antiguo de la cuenca mediterránea (Baldellou et al. 1989), por lo que, a pesar de la ausencia de datos claros sobre su procedencia, resulta un buen indicador de la existencia de ocupaciones neolíticas en la cavidad.

De estos 346 restos, 138 aparecen asociados a un genérico Upper layers, en el que es imposible discriminar su procedencia exacta. Este conjunto nuevamente destaca por la importancia del sílex (87 restos frente a 45 de cuarcita) (Tabla 2), aunque en este caso el número de soportes laminares es menor $(\mathrm{n}=29)$. Entre los útiles destacan dos percutores de cuarcita, un buril carenado, un núcleo de laminillas y varios fragmentos de núcleo; conviene indicar así mismo la presencia de una lasca Levallois (Tabla 3).

El Nivel I está formado por 149 restos individualizados además de 53 restos de talla, en una proporción de materias primas prácticamente idéntica a la del conjunto denominado Upper layers (Tabla 2), y de los que 43 están conformados por soportes laminares, varios de ellos retocados, destacando especialmente por su significación crono-cultural dos segmentos de círculo (G1 de la clasificación de Fortea (1973)). No obstante, en el Nivel I aparecen también un núcleo Levallois sobre lasca de sílex y un núcleo Quina en cuarcita, lo que refuerza la idea de la presencia de algunos elementos más antiguos mezclados entre el material postpaleolítico.

Finalmente, el Nivel II (subdividido en IIa y IIb) resultó más pobre, contabilizando un total de 56 restos líticos y 9 restos de talla, aunque también en este caso se repiten las características de los niveles superiores: predominio del sílex (Tabla 1) y abundancia de soportes laminares. El capítulo de útiles lo componen cuatro microlitos geométricos (dos trapecios y dos segmentos), una 


\begin{tabular}{|c|c|c|c|}
\hline Tipo & $\begin{array}{l}\text { Upper } \\
\text { Layer }\end{array}$ & $\begin{array}{c}\text { Nivel } \\
\text { I }\end{array}$ & $\begin{array}{c}\text { Nivel } \\
\text { II }\end{array}$ \\
\hline Raspador simple sobre lasca (R1) & & & 1 \\
\hline Raspador nucleiforme (R4) & & & 2 \\
\hline $\begin{array}{l}\text { Raspador en hombrera u hocico } \\
\text { (R6) }\end{array}$ & & 1 & \\
\hline $\begin{array}{l}\text { Raspador sobre lámina o } \\
\text { laminilla (R8) }\end{array}$ & & & 1 \\
\hline Raspador ojival (R10) & & 1 & \\
\hline Perforador simple (P) & & 1 & \\
\hline Raclette (LBA2) & & 1 & \\
\hline $\begin{array}{l}\text { Frag. laminilla de borde abatido } \\
\text { (lba11) }\end{array}$ & & & 1 \\
\hline Lasca con muesca (MD1) & & 1 & \\
\hline $\begin{array}{l}\text { Lámina o laminilla con muesca } \\
\text { (MD3) }\end{array}$ & & 3 & 2 \\
\hline $\begin{array}{l}\text { Lámina o laminilla denticulada } \\
\text { (MD4) }\end{array}$ & & 2 & \\
\hline Medialuna (G1m) & & 1 & \\
\hline Segmento (G1s) & & 1 & 1 \\
\hline Segmento o Medialuna (G1) & & & 1 \\
\hline Trapecio simétrico (G2) & & & 2 \\
\hline Ápice triédrico (M2) & & 1 & \\
\hline Pieza con retoque continuo (D2) & & 1 & \\
\hline Raedera & & & 1 \\
\hline Pieza foliácea apuntada (D5) & & 2 & \\
\hline Núcleo & 1 & 2 & \\
\hline Percutor & 2 & & \\
\hline Buril & 1 & & \\
\hline Diversos (D8) & & 1 & \\
\hline TOTAL & 4 & 19 & 12 \\
\hline
\end{tabular}

Tabla 3. Útiles retocados procedentes de los niveles superiores de la Cueva del Niño, correspondientes a las dos zonas de excavación (Trench 1 - Trench 2 y TAL). Clasificación según Fortea 1973. laminilla de dorso y cuatro raspadores, además de una raedera (Tabla 3 ).

Por otra parte, un total de 151 restos líticos no presentan adscripción estratigráfica exacta a un nivel concreto, aunque teniendo en cuenta los tramos de los que proceden y sus características es probable que la mayoría de ellos correspondan a los niveles superiores de la secuencia. En general este conjunto se caracteriza por el predominio del sílex $(\mathrm{n}=125,81,16 \%)$ (Tabla 2$)$ y por el elevado número de soportes laminares $(\mathrm{n}=42$ entre láminas, fragmentos de lámina o laminillas, la práctica totalidad en sílex), e incluye dos núcleos de laminillas, ambos en sílex.

En definitiva, la industria lítica de la Cueva del Niño muestra en general un carácter postpaleolítico, que encaja con un contexto neolítico, aunque resulta imposible discriminar entre un único momento de ocupación neolítico o por el contrario la existencia de dos fases, periodos además poco diferenciados en la zona de la Sierra del Segura (Juan-Cabanilles 2008; Rodríguez González 2008). Por otra parte, la probable inclusión de elementos más antiguos, de cronología paleolítica, dificulta la interpretación cuantitativa del conjunto, del que tan sólo puede destacarse el dominio del sílex, su elevada laminaridad y la presencia de elementos característicos de las industrias postpaleolíticas, como microlitos geométricos.

\section{Análisis de la fauna de mamíferos}

Los restos de fauna procedentes de los niveles superiores de la secuencia estratigráfica, estudiados previamente por Davidson (1981, Capítulo 10) fueron revisados empleando una metodología arqueozoológica moderna, incluyendo un análisis tafonómico de la muestra, del que se carecía anteriormente. Este estudio se llevó a cabo en el Grahame Clark Laboratory de la Universidad de Cambridge, puesto que el material óseo seguía depositado en dicha universidad británica.

Se identificaron a nivel taxonómico un total de 273 restos, de los que 75 lo fueron a nivel de especie o familia, mientras que los 198 restantes tan sólo pudieron ser asignados a una de las tres categorías definidas en función de la talla ("Mamífero de talla pequeña, mediana y grande"). Un 54\% de los restos identificados corresponden a la zona TAL (Tabla 4), mientras que Trench 1 y Trench 2 


\begin{tabular}{|c|c|c|c|c|c|c|c|c|c|}
\hline \multirow{2}{*}{ Taxón } & \multicolumn{3}{|c|}{ Nivel I } & \multicolumn{3}{|c|}{ Nivel II } & \multirow{2}{*}{$\frac{\text { Nivel III }}{\text { TAL* }}$} & \multirow{2}{*}{$\frac{\text { Nivel IV }}{\text { TAL* }}$} & \multirow{2}{*}{ Total } \\
\hline & TAL & Trench 1 & Trench 2 & TAL & Trench 1 & Trench 2 & & & \\
\hline Equus sp. & & 1 & & & & & & & 1 \\
\hline Cervus elaphus & 2 & & & & & & & & 2 \\
\hline Rupicapra rupicapra & & & 3 & & & & & & 3 \\
\hline Ovicápridos & 4 & & 3 & 3 & & 12 & 1 & 9 & 32 \\
\hline Oryctolagus cuniculus & 11 & 1 & 3 & 4 & 1 & & 7 & 5 & 32 \\
\hline Canis sp. & & & & & & & 1 & & 1 \\
\hline Mamífero grande & & 4 & & & 1 & & & & 5 \\
\hline Mamífero medio & 47 & 39 & 12 & 19 & 30 & 13 & 14 & 18 & 195 \\
\hline Mamífero pequeño & & 1 & 1 & & & & & & 2 \\
\hline TOTAL & 67 & 46 & 22 & 26 & 32 & 25 & 23 & 32 & 273 \\
\hline
\end{tabular}

* Los niveles III y IV de Trench 1 y Trench 2 corresponden al Paleolítico Medio.

Tabla 4. Número de restos identificados (NR) en los niveles superiores de la Cueva del Niño.

resultaron más pobres en material óseo $(29 \%$ y $17 \%$ respectivamente). No obstante ambas zonas de excavación no son equiparables puesto que no se ha podido establecer correlación alguna entre sus distintos niveles, sin olvidar la posible inclusión de materiales más antiguos en Trench 1 y 2. Así pues, nos centraremos fundamentalmente en la información proporcionada por la zona de excavación TAL, comentando someramente los datos de Trench 1 y 2 .

En general, el estado de conservación de la muestra es deficiente, con un elevado grado de fragmentación, lo que limitó la identificación taxonómica y anatómica. La disolución afectó tanto a la superficie interna como externa de los huesos, impidiendo observar la posible existencia de alteraciones de carácter antrópico. Las escasas modificaciones antrópicas identificadas muestran marcas de corte en una tibia y un radio de mamífero medio en TAL y trazas de descarnado en un hueso largo de mamífero grande, posiblemente caballo. En TAL un 46\% de los restos aparecían quemados, mientras que en los niveles I y II de Trench 1 y Trench 2 esta cantidad se limitaba al $9 \%$ y $8,5 \%$, respectivamente. Igualmente en el $8,4 \%$ de los huesos se han observado patrones de fracturación en fresco $(4,4 \%$ en TAL, $2,6 \%$ en Trench 1 y $1,5 \%$ en Trench 2).

En el Nivel I, el taxón más representado es el conejo (Tabla 4). El origen antrópico de los restos de conejo en yacimientos holocenos del
Levante peninsular ha sido discutido en diversas ocasiones, y aunque no puede obviarse el aporte realizado por depredadores, parece claro que las poblaciones humanas fueron un agente acumulador destacado (Aura Tortosa et al. 2006; García del Toro 1984). En la Cueva del Niño se identificaron un fragmento de pelvis y otro de tibia que parecen indicar un consumo antrópico, si bien el pobre estado de conservación de la superficie ósea ha impedido conocer más sobre los hábitos de consumo humano de los lepóridos, por lo que la valoración sobre su papel en la dieta neolítica es limitado. Sin embargo, son los ovicápridos los que mayor representatividad tienen en la dieta y muchos de los restos de la talla de mamífero medio, muy posiblemente podrían corresponder a este grupo. Completan la muestra un resto dental y una falange de Cervus elaphus. La situación es similar para Trench 1 y Trench 2, donde también son abundantes los restos de mamíferos de talla media, a los que se añaden un diente de caballo en Trench 1 , junto a tres restos dentales de rebeco en Trench 2.

Los niveles infrayacentes II, III y IV (estos últimos sólo representados en TAL) muestran una imagen similar (Tabla 4), con un claro predominio de ovicápridos, junto a un elevado porcentaje de restos pertenecientes a mamíferos de talla media, posiblemente de esta misma asignación taxonómica. En este caso, destaca la presencia de un fragmento mandibular de cánido en el Nivel III de TAL. 
En definitiva, el conjunto arqueozoológico de la Cueva del Niño representa el medioambiente circundante a su localización ecológica correspondiente al periodo de estudio. Desgraciadamente, la escasez de la muestra y su limitada conservación no permiten conocer, más ampliamente, la importancia en la dieta de los taxones recuperados y las labores de manipulación antrópica de los animales consumidos.

\section{Datación del depósito}

Uno de los objetivos principales de la revisión del conjunto arqueológico de la Cueva del Niño era conocer la cronología del depósito, hasta el momento sólo planteada a partir de las industrias (lítica y cerámica) y el ritmo de sedimentación estimado (Davidson 1981, Capítulo 10; Higgs et al. 1976). Con la intención de precisar la cronología de las distintas ocupaciones humanas de la cavidad se llevó a cabo un programa de datación. Este programa se completa con una datación radiocarbónica efectuada por Davidson en 1973 (Davidson y García Moreno 2013).

Para la Trinchera Arte Levantino, se seleccionó un astrágalo y varios fragmentos de hueso procedentes del nivel IIb, con un peso total de 20.5 gr., que fueron enviados para su datación mediante radiocarbono al GADAM Centre (Gliwice Absolute Dating Methods) de la Silesian University of Technology, Polonia. Esta datación arrojó una fecha de 5199 - 4843 cal BC (Tabla 5), que resulta coherente con la adscripción neolítica de este nivel.

Por su parte, en 1973 se dató una muestra de carbón procedente del Nivel II de Trench 2 en el Radiocarbon Dating Laboratory de la Universidad de Birmingham. El resultado de esta datación, estimada en 6011 - 5727 cal BC (Tabla 5 ), plantea ciertos problemas, puesto que parece un tanto antigua para un conjunto neolítico. Esta datación podría indicar por lo tanto la existencia de ocupaciones anteriores en la cavidad, que en el caso de la Cueva del Niño resultan imposibles de diferenciar de las ocupaciones neolíticas desde el punto de vista estratigráfico o tecno-tipológico. Por otra parte, también cabe la posibilidad de que se tratase de un carbón de alguna especie longeva, lo que podría producir un efecto de "madera vieja", arrojando una datación más antigua que la del nivel donde fue recuperado y por lo tanto envejeciendo su cronología.

Más reservas aún plantean las dos dataciones obtenidas mediante el método de Racemización de Aminoácidos (AAR) en el Laboratorio de Estratigrafía Biomolecular de la Universidad Politécnica de Madrid. Mediante este método se dataron sendas piezas dentarias de Capra sp. procedentes del Nivel II de Trench 2, que resultaron en una antigüedad de $110.31 \mathrm{ka}$ BP y $73.81 \mathrm{ka}$ BP. Estas dataciones, a todas luces inconsistentes con la posición estratigráfica del estrato (García Moreno et al. 2014), con la datación radiocarbónica y con la mayor parte del registro material del mismo (industrias microlíticas y cerámica), podrían indicar la intrusión de materiales más antiguos en los niveles superiores del depósito, aunque también podrían deberse a problemas de datación causados por la posible alteración de las muestras. Este punto será tratado con mayor detalle en la discusión.

\section{Arte rupestre}

Además del depósito arqueológico, la Cueva del Niño presenta también una serie de representaciones pictóricas rupestres, típicamente características del estilo Levantino, y que ya fueron documentadas por Almagro en su trabajo sobre el yacimiento (Almagro Gorbea 1971). Estas pinturas se localizan en el abrigo exterior, a la derecha de la boca de la cavidad. Todas ellas fueron realizadas en diferentes tonalidades de rojo, y se encuentran en la actualidad muy deterioradas por el desprendimiento de parte del soporte y por el hollín adherido a la superficie.

\begin{tabular}{|l|c|c|c|c|c|c|}
\hline \multicolumn{1}{|c|}{ Sondeo } & Nivel & Lab. ID & C14 BP & cal BC* & Material & Método \\
\hline Trench 2 & II & Birm-1113 & $6990 \pm 80$ & $6011-5727$ & carbón & C14 Conv. \\
\hline TAL & IIb & GdA-2102 & $6065 \pm 40$ & $5199-4843$ & hueso & AMS \\
\hline Trench 2 & II & LEB-9576 & $110.31 \mathrm{ka}$ & - & hueso & AAR \\
\hline Trench 2 & II & LEB-9577 & $73.81 \mathrm{ka}$ & - & hueso & AAR \\
\hline
\end{tabular}

* OxCal 4.2, Curva IntCal 13.

Tabla 5. Dataciones disponibles para los niveles superiores de la Cueva del Niño. 


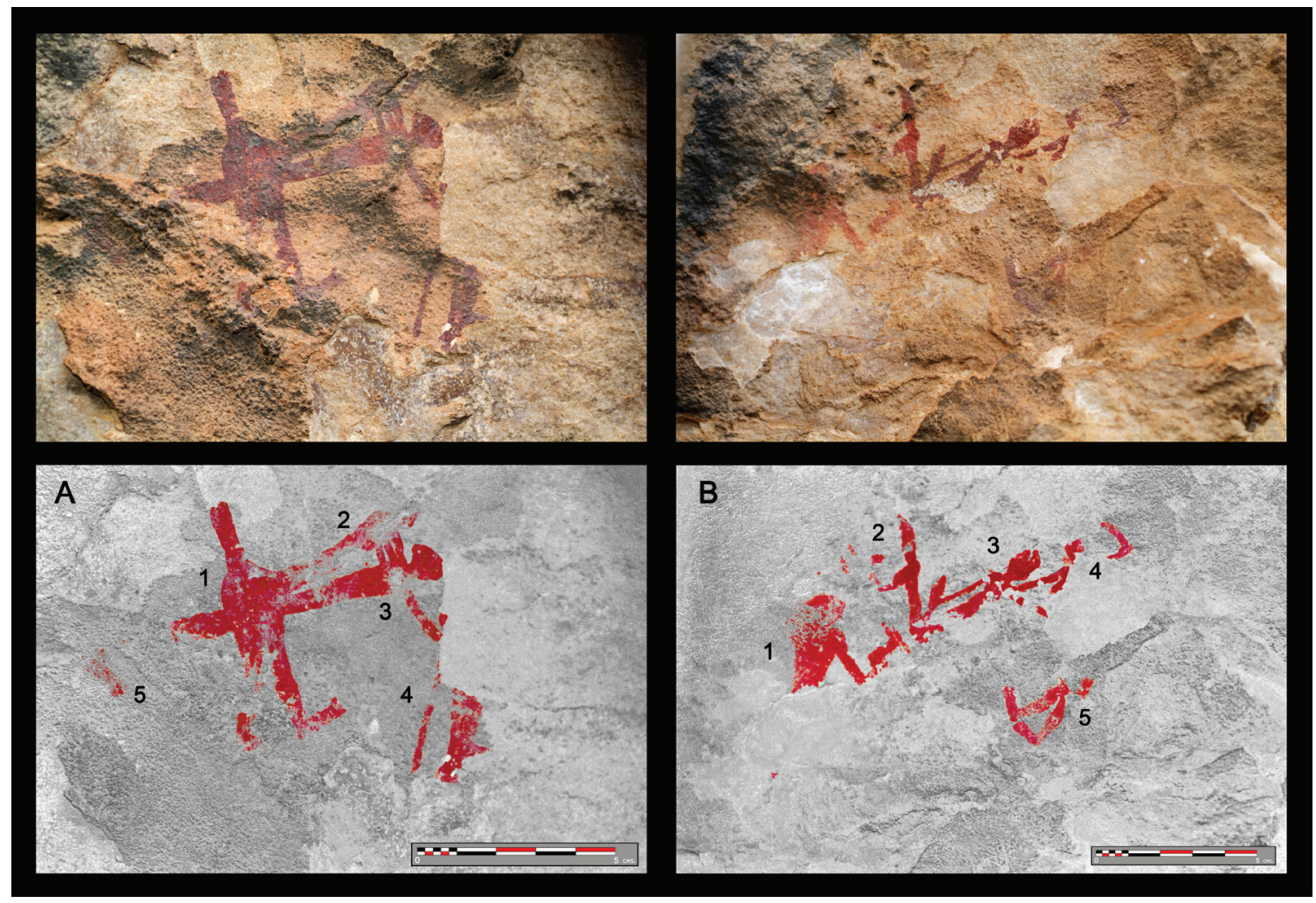

Fig. 9. Fotografía y calco de las pinturas de estilo Levantino de la Cueva del Cueva del Niño, situadas sobre el sondeo TAL (Garate Maidagan).

Se trata de dos conjuntos de representaciones separadas por tan sólo $10 \mathrm{~cm}$, por lo que podrían considerarse que forman un único panel decorativo (Fig. 9).

El conjunto situado a izquierda (Fig. 9A) es el más cercano a la boca de la cueva. Se pueden discriminar cinco motivos de los que tres son figuras humanas, mientras que una cuarta figura podría corresponder también con una representación humana, siendo la quinta un resto fragmentario de colorante que quizás se pueda corresponder con los pies del motivo ${ }^{0} 3$. Dos de las figuras humanas ( 1 y 3 ) se disponen entrecruzadas; una en vertical con los pies detallados y la cabeza esquematizada, otra en horizontal a la altura del tronco de la anterior, con las extremidades superiores indicadas, la cabeza redondeada y el tronco cortado en el extremo inferior, aunque quizás continúa en el motivo ${ }^{0}$ 5. En paralelo a esta representación humana se observa otra figura horizontal (2), mucho más esquematizada y peor conservada, que podría corresponderse con otra representación humana, con reservas en todo caso. Por debajo de este grupo se observa el tronco, el arranque de las piernas y parte del brazo de otra figura humana (4).

El conjunto situado más a la derecha (Fig. 9B) está formado también por cinco motivos, todos ellos representaciones humanas. Las cuatro primeras representaciones se encuentran alineadas de manera ascendente. A izquierda se observa la parte superior de la figura humana en vertical (1), con cabeza redondeada, tronco y una extremidades superior, cortada por un desconchado. A su derecha, también en vertical se observa una forma alargada menos definida (2) que pudiera representar otro humano. Un tercer motivo (3), inclinado $45^{\circ}$, presenta el tronco estrecho, la cabeza redondeada y dos brazos de un humano, sin que parezca que las piernas hayan sido indicadas. Seguida y también inclinada, se observan las dos extremidades superiores y la cabeza de una cuarta figura (4), muy fragmentada por el desconchado de la pared. Por debajo de este conjunto se conservan las piernas, con los pies detallados, y arranque del tronco de otro humano (5). Aunque le separa un desprendimiento del motivo $\mathrm{n}^{\circ} 4$, la inclinación y distancia entre ambas nos sugiere que se trata de figuras humanas distintas. 
En definitiva, y considerando las limitaciones derivadas del mal estado de conservación del conjunto, diferenciamos ocho representaciones humanas, otra posible y un motivo que correspondería con las extremidades inferiores de una de las figuras señaladas.

Desgraciadamente, los datos con los que contamos en la actualidad para las representaciones de la Cueva del Niño no arrojan mucha luz sobre el debate en torno a la cronología del arte Levantino y la naturaleza de sus autores, ya que se ha propuesto tanto su realización por parte de comunidades mesolíticas indígenas asentadas en la zona de la Sierra como por parte de grupos neolíticos (Alonso y Grimal 1994; García Atiénzar 2011; Mateo Saura 1997-1998). Las pinturas se localizan directamente sobre la Trinchera Arte Levantino. La obtención de una datación de finales del $\mathrm{VI}^{\circ}$ - inicios del $\mathrm{V}^{\circ}$ milenio al pie de este panel es un indicador a considerar, aunque no es posible establecer una relación directa entre esta datación y las pinturas, por lo que no se pueden descartar otras cronologías, máxime si tenemos en cuenta la amplia secuencia de ocupación de la cavidad.

\section{Discusión: la ocupación neolítica de la Cueva del Niño y la neolitización en la Sierra del Segura}

El primer punto a analizar a la hora de valorar la ocupación de la Cueva del Niño durante el Neolítico es la propia integridad del depósito arqueológico. Como ya se ha mencionado en diversos puntos de este trabajo, existen algunos indicios que parecen indicar la presencia de elementos intrusivos en los niveles superiores de la secuencia estratigráfica definida en las dos trincheras exteriores, Trench 1 y Trench 2, fundamentalmente la presencia de industrias líticas de aspecto arcaico, de gran formato y realizadas en cuarcita, incluyendo la existencia de un núcleo de tipo Levallois, así como las dos dataciones obtenidas mediante AAR sobre dos dientes de cabra, que remiten al Pleistoceno Medio. Estos materiales podrían proceder de un sondeo realizado en el vestíbulo de la cavidad, justo frente a la boca, fruto de una remoción descontrolada de sedimento con fines desconocidos; este sondeo se efectuó con anterioridad a la excavación arqueológica, como queda atestiguado por fotografías de prensa del año 1970 (ABC,11 de Octubre de 1970), en las que se daba cuenta del descubrimiento de la cavidad. Así pues, materiales procedentes de dicho sondeo se habrían redepositado en el exterior de la cavidad y mezclado con los niveles superiores de la secuencia.

Sin embargo, durante el proceso de excavación no se apreció ninguna alteración de este tipo en el depósito arqueológico. Por otra parte, la mayor parte de la industria lítica de los niveles superiores muestra un aspecto homogéneo y claramente postpaleolítico, por lo que Davidson consideró que la presencia de líticas de gran formato podría deberse a una adaptación local a la materia prima existente en el entorno de la cavidad, de manera similar a lo planteado para el Paleolítico Superior (Davidson 1991). Por otra parte, en el nivel $1 \mathrm{~b}$ del yacimiento de la Cueva Blanca en Hellín, atribuido al Mesolítico geométrico, se documenta una considerable producción de lascas y un uso dominante de la cuarcita, junto a una producción laminar y la presencia de geométricos (Mingo et al. 2012).

En cualquier caso, y ante la imposibilidad de aclarar las dudas existentes sobre la integridad de los niveles superiores de Trench 1 y Trench 2 , y a falta de nuevas excavaciones y análisis, preferimos adoptar una postura conservadora al respecto, valorando la información que aportan pero centrando la interpretación del depósito en los datos arrojados por la Trinchera Arte Levantino. En cualquier caso, y a pesar de estas reservas, pueden apuntarse algunas conclusiones que ayuden a interpretar las ocupaciones de este yacimiento durante el Neolítico peninsular.

En primer lugar, es factible plantear una ocupación entre finales del VI o comienzos del V milenio cal BC en la Cueva del Niño. Esta adscripción se basa tanto en la datación radiocarbónica obtenida para el nivel II del sondeo TAL, cuya integridad estratigráfica no presenta dudas, como en las características morfológicas y decorativas de las producciones cerámicas procedentes de ese mismo nivel, con paralelos de cronología similar en el sureste peninsular (Bernabeu Auban et al. 2011; Gavilán Ceballos et al. 1996) e incluso en el entorno de la Sierra del Segura, como el nivel A de la Cueva del Nacimiento, datado en el 4830 BC (Rodríguez 1979) (Tabla 6). De igual manera cabe plantear la posibilidad de que las pinturas rupestres Levantinas, situadas directamente sobre el nivel datado fuesen realizadas en esta fecha, aunque dado que no es posible establecer una relación directa entre dicha datación y las propias figuras, resulta imposible concretar la cronología del arte Levantino en el yacimiento y, por exten- 
sión, en la región (Alonso y Grimal 1994; García Atienzar 2011; Mateo Saura 1997-1998). Por el contrario, la fecha de 6011 - 5727 cal BC obtenida en el nivel II de Trench 2 es demasiado antigua para el Neolítico de la zona, mientras que es más reciente que el epipaleolítico del Abrigo del Molino del Vadico, datado en torno a 6450 cal BC (Vega Toscano 1993). Dada la caracterización tecnotipológica de la industria lítica y la existencia de cerámica en el estrato, así como la imposibilidad de concretar la especie sobre la que se llevó a cabo la datación (puede que longeva), es razonable suponer que el contexto cultural sea efectivamente neolítico, no necesariamente tan antiguo como apunta el resultado de la datación. Otra posibilidad, con menos argumentos a su favor ya que no está apoyado ni por la estratigrafía ni por la industria lítica ni cerámica del estrato, es que dicha datación sea fiable y corresponda a la ocupación del yacimiento durante el Mesolítico.

La industria lítica procedente de los niveles superiores de la secuencia es difícil de valorar, ya que por una parte no es posible discriminar completamente qué elementos proceden del sondeo TAL y cuáles proceden de Trench 1 y Trench 2 , con las consiguientes dudas sobre la integridad del conjunto lítico. Por otra parte, en el momento de la excavación no fue posible diferenciar entre distintos niveles de ocupación, lo que impide concretar si la industria lítica pertenece íntegramente a un conjunto neolítico (aun obviando la posible contaminación con material antiguo) o si por el contrario se trata de dos conjuntos diferentes. En cualquier caso, resulta evidente el carácter postpaleolítico de la mayoría del conjunto, con una elevada laminaridad y la presencia de microlíticos geométricos. El empleo dominante del sílex, materia prima que no ha sido localizada en las inmediaciones de la cavidad, así como la elevada laminaridad, la presencia de diversos núcleos y la escasez de productos de decorticado, sugieren la introducción en el yacimiento de útiles conformados y núcleos preparados, puede que destinados al mantenimiento de armamento de caza. No obstante, dado que resulta imposible establecer el papel jugado por los soportes más masivos realizados sobre cuarcitas locales, no es posible interpretar con exactitud la industria lítica del yacimiento.

Algo similar puede decirse de la fauna de mamíferos, ya que su pobre estado de conservación impidió la identificación taxonómica de un elevado número de restos, así como la observación de posibles alteraciones antrópicas. Por otra par- te, el hecho de que dos restos óseos procedentes del nivel II de Trench 2 arrojasen una cronología pleistocena plantea dudas sobre la procedencia de parte de los restos. La muestra, tanto si nos centramos tan sólo en los restos de fauna procedentes del sondeo TAL como si consideramos todo el conjunto, está dominada por ovicápridos y por ungulados de talla media. Desgraciadamente, el mal estado de conservación impidió concretar si se trata de cabra salvaje o si por el contrario nos encontramos ante especímenes ya domesticados. Por otra parte, Davidson (1989) apuntó la posibilidad de que la presencia de restos de ovicápridos domésticos en el yacimiento podría deberse a que algunos ejemplares, fugados de sus rebaños, fuesen cazados por poblaciones mesolíticas autóctonas.

Ello impide confirmar el desarrollo de prácticas relacionadas con el pastoreo, como por ejemplo el cierre de ganado en este yacimiento, y en cualquier caso la presencia de ovicápridos domésticos en el yacimiento podría deberse a actividades distintas del pastoreo, como su transporte y consumo. No obstante, otras evidencias apuntan a la posible existencia de un depósito de redil en el yacimiento. En primer lugar la presencia en la zona del vestíbulo (y puede que en TAL) de una secuencia cuyas características estratigráficas y macro sedimentológicas (acumulaciones limosas relativamente homogéneas con escasa fracción gruesa en la que se alternan capas de color blanquecino, gris claro y gris oscuro) (Fig. 10) presentan similitudes con las registradas en depósitos neolíticos y calcolíticos del norte y levante peninsular en los que se ha confirmado la existencia de rediles a través de análisis microestratigráficos (Angelucci et al. 2009; Bergadà 1997, 2001; Bergadà et al. 2005a, 2005b; JuanCabanilles et al. 2005; Polo-Díaz y Fernández Eraso 2010; Verdasco 2001, 2002).

En segundo lugar la alta fragmentación que muestran tanto los restos óseos como cerámicos y los signos de alteración térmica que presentan muchos restos óseos (en TAL los huesos quemados alcanzan el $46 \%$ ) son igualmente rasgos documentados de manera frecuente en depósitos de redil. Dichos rasgos son atribuibles al uso especializado de estos sitios como apriscos y están relacionados por un lado con procesos de alteración postdeposicional de los restos acumulados a través del pisoteo de los animales encerrados y por otro con prácticas de limpieza que se llevan a cabo mediante la quema de residuos (Polo-Díaz 2009; Polo-Díaz et al. 2014). No obstante, a falta 


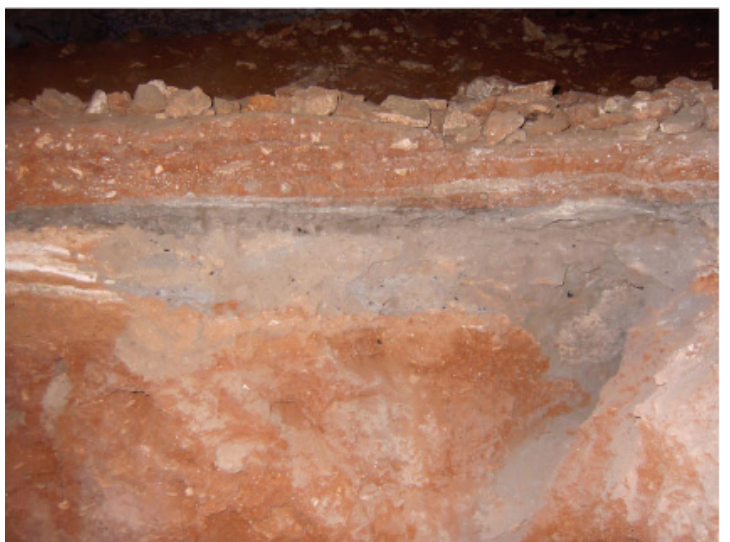

Fig. 10. Detalle del fumier existente en el vestíbulo de la Cueva del Niño, cuyas características sedimentarias sugieren la presencia de un depósito de redil (García Moreno).

de un análisis sedimentológico detallado de estos niveles no es posible contrastar la existencia de un depósito de redil en la cueva.

Aunque se recuperaron algunos restos macrobotánicos en niveles más antiguos de la secuencia, los métodos de excavación de 1973 no favorecieron la recuperación de restos carpológicos que pudieran arrojar luz sobre el papel jugado por los recursos vegetales entre las poblaciones que ocuparon el yacimiento. Aunque se dispone de datos relativamente abundantes para comprender la introducción en el Neolítico Antiguo de especies vegetales domésticas y su papel en el proceso de neolitización en la costa mediterránea, el interior peninsular sigue estando insuficientemente conocido por el momento y basado en la evidencia proporcionada por escasos yacimientos (Peña-Chocarro 2007; Peña-Chocarro y Zapata 2010; Peña-Chocarro et al. 2013).

Con la información disponible, el yacimiento de la Cueva del Niño aparece como un asentamiento temporal y esporádico, probablemente destinado al pastoreo de ovicápridos, aunque a falta de concretar la existencia de un redil de ganado en la cavidad, no puede descartarse que la presencia de restos de ovicápridos se debiese a otras actividades. Junto al posible pastoreo también se llevarían a cabo actividades cinegéticas, centradas principalmente en lepóridos $\mathrm{y}$, en menor medida, ciervos y puede que cabras silvestres, atestiguadas por la presencia de armamento de caza, como microlitos y laminillas, además de por los propios restos faunísticos. Dicho armamento se introduciría en su mayor parte conformado o semiconformado en forma de núcleos; por lo tanto, las actividades de talla se centrarían fundamentalmente en las últimas fases de la cadena operativa y en el mantenimiento del armamento de caza. De igual manera, aunque la materia prima empleada en las producciones cerámicas es compatible con el entorno geológico en el que se localiza la cavidad, no parece que estas fuesen producidas en el propio yacimiento; igualmente, la elevada fragmentación del conjunto así como la ausencia de remontajes sugieren que estamos ante un contexto de descarte, lo que refuerza la hipótesis de un uso esporádico, y no habitacional, del yacimiento.

Desde un punto de vista regional, la Cueva del Niño presenta claras similitudes con otros conjuntos de la Sierra del Segura (García Moreno 2014), como el nivel A1.1 del Abrigo del Molino del Vadico (Vega Toscano 1993) o el nivel A/II la Cueva del Nacimiento (Asquerino y López 1981; Rodríguez González 1979); en ambos conjuntos, la industria lítica de tipo laminar y microlaminar es dominante, realizada sobre sílex, y en ambos aparecen microlitos geométricos. El espectro faunístico de estos yacimientos es similar al observado en El Niño, dominado por cabras (puede que combinando especímenes tanto salvajes como domésticos), con una gran importancia de los restos de lepóridos. Finalmente, las producciones cerámicas son variadas, aunque basándose en los motivos decorativos se pueden adscribir al Neolítico Antiguo de la región. No obstante, las dataciones radiocarbónicas disponibles para la

\begin{tabular}{|l|c|c|c|c|c|c|c|}
\hline \multicolumn{1}{|c|}{ Yacimiento } & Nivel & Lab. ID & C14 BP & cal BC* & Material & Método & Referencia \\
\hline Cueva del Niño & $\begin{array}{c}\text { IIb } \\
\text { (TAL) }\end{array}$ & GdA-2102 & $6065 \pm 40$ & $5199-4843$ & hueso & AMS & - \\
\hline C. del Nacimiento & A-2 & GIF-1368 & 6780 & $5714-5647$ & - & - & Rodríguez 1979 \\
\hline C. del Nacimiento & A-2D & GIF-5422 & $5490 \pm 120$ & $4586-4005$ & - & - & Asquerino 1981 \\
\hline
\end{tabular}

* OxCal 4.2, Curva IntCal 13.

Tabla 6. Dataciones radiocarbónicas disponibles para los conjuntos adscritos al Neolítico antiguo en la Sierra del Segura. 
Cueva del Nacimiento son o más antiguas o más recientes que aquella con la que contamos en El Niño (Tabla 6), lo que dificulta definir una horquilla temporal para el Neolítico Antiguo en la Sierra del Segura.

Así pues, los datos aportados por la Cueva del Niño, junto a la evidencia existente en otros yacimientos de la región, parecen apoyar el modelo de explotación del territorio y asentamiento propuesto para el primer Neolítico en la Sierra del Segura (García Atiénzar 2010; Rodríguez González 1997), según el cual los yacimientos de montaña actuarían como refugios temporales durante las actividades de pastoreo, posiblemente de carácter estacional y trashumante, realizadas por comunidades asentadas en tierras más bajas. La práctica de cierto pastoreo implica la desaparición de actividades cinegéticas, que seguirían teniendo una importancia considerable en las comunidades que ocupaban la Sierra a mediados del Holoceno.

Desgraciadamente, la indefinición cultural de los niveles superiores de Trench 1 y Trench 2, que no permite concretar la posible existencia o ausencia de ocupaciones anteriores al Neolítico, unido a la posibilidad de que la datación obtenida para el Nivel II esté envejecida por un efecto de "madera vieja" sobre la muestra datada, impiden valorar el carácter o funcionalidad de la cavidad durante el proceso de introducción de la economía de producción en la cuenca del río Mundo y la Sierra del Segura en particular (Rodríguez González 2008), y en un contexto más amplio, en el sureste peninsular en general (Berrocal 2012). La presencia de industria lítica destinada posiblemente a armamento de caza en el Niño, así como la existencia de fauna salvaje, indica la pervivencia de unas bases de subsistencia en las que la actividad cinegética mantenía una cierta importancia. Tradicionalmente, se ha planteado que yacimientos como el de la Cueva del Niño pudieron funcionar como estaciones de caza o campamentos estacionales (García Atiénzar 2011: 221). En este sentido, cabría hablar más de algún tipo de aculturación o asimilación de determinados elementos neolitizadores por parte de las sociedades que poblaban la zona con anterioridad, integradas en unos patrones de gestión del territorio y movilidad amplios en los que los yacimientos de la sierra actuaban a modo de "satélites" de otros asentamientos de mayor entidad (García Atiénzar 2011), a la vez que mantenían las formas de vida desarrolladas a lo largo del Mesolítico (Mateo Saura 1997-1998; Mingo et al. 2012).

\section{Conclusiones}

La revisión y análisis del material arqueológico recuperado en la excavación de 1973 de la Cueva del Niño ha permitido caracterizar las ocupaciones neolíticas del yacimiento. Esta caracterización es necesariamente cautelosa, debido a las limitaciones que presenta enfrentarse al estudio de los materiales obtenidos en una excavación arqueológica realizada hace 40 años, así como a las dudas que ofrece la integridad estratigráfica de los niveles superiores de las trincheras denominadas Trench $1 \mathrm{y}$ Trench 2, lo que por ejemplo impide diferenciar entre las ocupaciones neolíticas y un posible uso anterior de la cavidad.

A pesar de estas limitaciones, ha sido posible identificar una secuencia estratigráfica en el sondeo Trinchera Arte Levantino, que sitúa la ocupación de la cavidad probablemente a finales del VI y comienzos del $\mathrm{V}$ milenio cal BC, momento al que podrían corresponder la pinturas de estilo Levantino situadas justo sobre este sondeo. Los datos aportados por el material arqueológico apuntan al uso de la cavidad relacionado con el pastoreo, posiblemente como redil de ganado caprino, más que como lugar de habitación. Además la actividad cinegética seguía mantenido cierta importancia durante este periodo, complementando al pastoreo. Por otra parte, dada la evidencia disponible, se desconoce el papel jugado por los recursos vegetales en estas poblaciones.

Por sus características y similitudes con otros yacimientos de la Sierra del Segura, el yacimiento de la Cueva del Niño se integraría en un territorio mayor, como parte de una serie de estaciones de montaña destinadas al pastoreo y la caza, que actuaban como satélites de otros asentamientos de mayor entidad. Sin embargo, dadas las dificultades para analizar la relación entre posibles ocupaciones de la cueva del Niño, resulta imposible por el momento valorar el proceso de introducción de la economía de producción en este yacimiento en particular y en la Sierra del Segura en general. Futuros análisis como el estudio del fumier existente en el vestíbulo de la cavidad, o nuevas excavaciones que permitan comprobar la integridad estratigráfica de los niveles superiores del depósito, posibilitarán una mejor definición de las ocupaciones neolíticas de la Cueva del Niño así como del proceso de neolitización del interior sureste peninsular. 
Nota

1. En el cálculo de los grosores únicamente se han considerado aquellos fragmentos que conservaban ambas superficies.

\section{Agradecimientos}

El estudio de los materiales arqueológicos de la Cueva del Niño y el programa de dataciones radiocarbónicas han sido financiados por el Instituto de Estudios Albacetenses "Don Juan Manuel" mediante diversas Ayudas a la Investigación. Queremos agradecer especialmente a Iain Davidson su predisposición y ayuda, lo que ha posibilitado la revisión de la excavación del yacimiento y sus materiales. También queremos agradecer a Jessica Ripengal su ayuda en el Grahame Clark Laboratory del McDonald Institute for Archaeological Research, al Museo Arqueológico de Albacete, y en especial a Blanca Gamo, por su ayuda para la consulta de los materiales allí depositados, así como a Jesús Moreno González y Juan Ángel Martínez por su apoyo. El análisis cerámico fue efectuado en el Instituto Internacional de Investigaciones Prehistóricas de Cantabria (IIIPC) y en el Departamento de Ciencias de la Tierra y Física de la Materia Condensada (CITIMAC) de la Universidad de Cantabria. A.B. Marín Arroyo es actualmente Investigadora Ramón y Cajal (RYC-201100695) en el IIIPC, Universidad de Cantabria.

\section{Referencias Bibliográficas}

Almagro Gorbea, M. (1971): La cueva del Niño (Albacete). La cueva de la Griega (Segovia). Dos yacimientos de arte rupestre recientemente descubiertos en la Península Ibérica. Trabajos de Prehistoria, 28: 9-62.

Alonso, A.; Grimal, A. (1994): Comentarios sobre el sector septentrional del Arte Levantino. Bolskan, 11: 9-31.

Angelucci, D. E.; Boschian, G.; Fontanals, M.; Pedrotti, A.; Vergès, J. M. (2009): Shepherds and karst: the use of caves and rock-shelters in the Mediterranean region during the Neolithic. World Archaeology, 41: 191-214. doi: 10.1080/00438240902843659.

Asquerino, M. D.; López, P. (1981): La cueva del Nacimiento (Pontones): un yacimiento neolítico en la Sierra del Segura. Trabajos de Prehistoria, 38: 109-152.

Aura Tortosa, J. E.; Carrión Marco, Y.; García Puchol, O.; Jardón Giner, P.; Jordá Pardo, J. F.; Molina Balaguer, L.; Morales Pérez, J. V.; Pascual Benito, J. L.; Pérez Jordá, G.; Pérez Ripoll, M.; Rodrigo García, M. J.; Verdasco Cebrián, C. C. (2006): Epipaleolítico-Mesolítico en las comarcas centrales valencianas. El mesolítico de muescas y denticulados en la cuenca del Ebro y el litoral mediterráneo peninsular. Memorias de yacimientos alaveses (A. Alday, ed.), Diputación Foral de Alava, Vitoria: 65-120.

Baldellou, V.; Mestre, I.; Martí, B.; Juan-Cabanilles, J. (1989): El Neolítico Antiguo. Los primeros agricultores y ganaderos en Aragón, Cataluña y Valencia. Diputación de Huesca, Huesca.

BergadÀ, M. M. (1997): Actividad antrópica en el Neolítico Antiguo catalán a través del análisis micromorfológico. Trabajos de Prehistoria, 54: 151-162. doi:10.3989/tp.1997.v54.i2.372.

BergadÀ, M. M. (2001): Análisis micromorfológico de los niveles neolíticos de la Cova de Cendres (Moraira, Teulada): resultados preliminares. La Cova de les Cendres (Teulada-Moraira, Alicante) (J. Bernabeu, M. P. Fumanal, E. Badal, eds.), Universitat de València, Valencia: 119-126.

BergadÀ, M. M.; Cebriá, A.; Mestres, J. (2005a): Prácticas de estabulación durante el Neolítico Antiguo en Cataluña a través de la micromorfología: cueva de la Guineau (Font-Rubí, Alt Penedès, Barcelona). III Congreso del Neolítico en la Península Ibérica, Santander 5-8 octubre 2003 (P. Arias Cabal, R. Ontañón Peredo, C. García-Moncó Piñeiro, eds.), Universidad de Cantabria, Santander: 187-196.

Bergadì, M. M.; Guerrero, V. M.; Ensenyat, J. (2005b): Primeras evidencias de estabulación en el yacimiento de Son Matge (Serra de Tramuntana, Mallorca) a través del registro sedimentario. Mayurca, 30: $153-180$. 
Bernabeu Auban, J.; Gómez Pérez, O.; Molina Balaguer, L.; García Borja, P. (2011): La cerámica neolítica durante el VI milenio cal AC en el Mediterráneo Central Peninsular. Las primeras producciones cerámicas: el VI milenio cal BC en la Península Ibérica (J. Bernabeu Auban,M. A. Rojo Guerra, L. Molina Balaguer, eds.), Saguntum (Papeles del Laboratorio de Arqueología de Valencia. Extra-12), Valencia: 153-178.

Berrocal, M. C. (2012): The Early Neolithic in the Iberian Peninsula and the Western Mediterranean: a review of the evidence on migration. Journal of World Prehistory, 25: 123-156. doi: 10.1007/s10963012-9059-9.

Davidson, I. (1981): Late Palaeolithic Economy in Eastern Spain. Tesis Doctoral inédita. University of Cambridge, Cambridge.

Davidson, I. (1986): The geographical study of Late Paleolithic stages in Eastern Spain. Stone Age Prehistory. (G. N. Bailey, P. Callow, eds.), Cambridge University Press, Cambridge: 95-118.

DAVIDSON, I. (1989): Escaped domestic animals and the introduction of agriculture in Spain. The Walking Larder: patterns of domestication, pastoralism and predation (J. Clutton-Brock, ed.), Unwin Hyman, London: $59-71$.

DAvidson, I. (1991): A great thick cloud of dust: Naming and dating in the interpretation of behaviour in the Late Paleolithic of Spain. Perspectives on the past. Theoretical biases in Mediterranean hunter-gatherer research. (G. A. Clark, ed.), University of Pennsylvania Press, Philadelphia: 194-204.

Davidson, I.; García Moreno, A. (2013): La excavación arqueológica de la Cueva del Niño (Ayna, Albacete) de 1973: secuencia estratigráfica y materiales. Al-Basit, 58: 91-117.

Fortea Pérez, F. J. (1978): Arte paleolítico del Mediterráneo español. Trabajos de Prehistoria, 35: 99-149.

Fortea Pérez, F. J. (1973): Los complejos microlaminares y geométricos del Epipaleolítico mediterráneo español. Universidad de Salamanca, Salamanca.

Garate Maidagan, D.; García Moreno, A. (2011): Revisión crítica y contextualización espacio-temporal del arte parietal paleolítico de la cueva de El Niño (Ayna, Albacete). Zephyrus, LXVIII: 15-39.

García AtiÉnzar, G. (2010): El yacimiento de Fuente de Isso (Hellin, Albacete) y el poblamiento neolítico en la provincia de Albacete. Serie I - Estudios, Núm. 193. Instituto de Estudios Albacetenses "Don Juan Manuel", Albacete.

García AtiÉnZar, G. (2011): El contexto arqueológico del Arte Rupestre Levantino en el Campo de Hellín (Albacete). Zephyrus, LXVIII: 63-86.

García del Toro, J. R. (1984): Representación del lepórido en las pinturas rupestres del Torcal de las Bojadillas (Nerpio, Albacete) y la fauna de lepóridos y lagomorfos en la prehistoria del Suroeste español. Congreso de historia de Albacete: 8-11 de diciembre de 1983, Vol. 1, 1984 (Arqueología y Prehistoria). Instituto de Estudios Albacetenses "Don Juan Manuel”, Albacete: 55-66.

García Moreno, A. (2014): El poblamiento paleolítico de la cuenca del río Mundo (Albacete). Archivo de Prehistoria Levantina, XXX: 1-16.

García Moreno, A.; Rios Garaizar, J.; Marín Arroyo, A. B.; Ortíz, J. E.; Torres, T.; López-Dóriga, I. (2014): La secuencia musteriense de la Cueva del Niño (Aýna, Albacete) y el poblamiento neandertal en el sureste peninsular. Trabajos de Prehistoria, 71 (2): 221-241. doi:10.3989/tp.2014.12132.

Gavilán Ceballos, B.; Vera Rodríguez, J.C.; Peña-Chocarro, L.; Mas, M. (1996): El V y el IV milenio en Andalucía Central: La Cueva de Los Murciélagos de Zuheros (Córdoba). Recientes aportaciones. I Congrés del Neolític a la Península Ibérica. Museu de Gavà (Rubricatum I), Gavà: 323-327.

Hernández Pérez, M. S. (2002): El poblamiento prehistórico de Albacete. Estado actual y perspectivas de futuro. II Congreso de Historia de Albacete: del 22 al 25 de Noviembre de 2000 en Albacete. Vol. 1. Prehistoria y Arqueología. Instituto de Estudios Albacetenses "Don Juan Manuel”, Albacete: 11-20.

Higgs, E.; Davidson, I.; Bernaldo De Quirós, F. (1976): Excavaciones en la Cueva de El Niño, Ayna (Albacete). Trabajos de Prehistoria, 5: 91-96.

Juan-Cabanilles, J. (2008): El utillaje de piedra tallada en la Prehistoria reciente valenciana. Trabajos Varios, Núm. 109. Servicio de Investigación Prehistórica del Museo de Prehistoria de Valencia, Valencia.

Juan-Cabanilles, J.; Martínez Valle, R.; Badal García, E.; Orozco Köhler, T.; Verdasco Cebrián, C. (2005): Un aprisco bajo abrigo en el yacimiento eneolítico de "El Cinto Mariano" (Requena, Valencia). 
III Congreso del Neolítico en la Península Ibérica, Santander 5-8 octubre 2003 (P. Arias Cabal, R. Ontañón Peredo, C. García-Moncó Piñeiro, eds.), Universidad de Cantabria Santander, Santander: 167-174.

Martí Oliver, B. (1988): Vaso neolítico procedente de la Cueva del Niño (Ayna, Albacete). Homenaje a Samuel de los Santos. Instituto de Estudios Albacetenses "Don Juan Manuel”, Albacete: 77-80.

Mateo Saura, M. A. (1997-1998): Arte rupestre y neolitización en el Alto Segura. Anales de Prehistoria y Arqueología, 13-14: 39-45.

Mingo, A.; Barca, J.; Mas, M.; López, J.; Benito, A.; Uzquiano, P.; Yravedra, J.; Cubas, M.; Avezuela, B.; Martín, I.; Bellardi, M. (2012): Caracterización del yacimiento de Cueva Blanca (Hellín, Albacete). Nuevas aportaciones para el debate en torno a la transición del Mesolítico al Neolítico antiguo en el Sureste peninsular. Complutum, 23: 63-75. doi: http://dx.doi.org/10.5209/rev_CMPL.2012.v23.n1.39531.

PeÑa-Chocarro, L. (2007): Early agriculture in central and southern Spain. The origins and spread of domestic plants in Southwest Asia and Europe (S. Colledge, J. Conolly, eds.), Institute of Archaeology, University College London. Left Coast Press, Walnut Creek: 173-188.

Peña-Chocarro, L.; Zapata, L. (2010): Neolithic agriculture in the southwestern Mediterranean region. Os últimos caçadores-recolectores e as primeiras comunidades produtoras do sul da Península Ibérica e do norte de Marrocos (J. F. Gibaja, A. F. Carvalho, eds.), Promontoria Monográfica 15, Universidade do Algarve, Faro: 191-198.

Peña-Chocarro, L.; Pérez Jordá, G.; Morales Mateos, J.; Zapata, L. (2013): Neolithic plant use in the Western Mediterranean region: preliminary results from the Agriwestmed project. Annali di Botanica, 3: 135-141. doi:10.4462/annbotrm-10306.

Polo-Díaz, A.; Martínez-Moreno, J.; Benito-Calvo, A.; Mora, R. (2014): Prehistoric herding facilities: site formation processes and archaeological dynamics in Cova Gran de Santa Linya (Southeastern Prepyrenees, Iberia). Journal of Archaeological Science, 41: 784-800. doi:10.1016/j.jas.2013.09.013.

Polo-Díaz, A.; Fernández Eraso, J. (2010): Same anthropogenic activity, different taphonomic processes: a comparison of deposits from Los Husos I \& II (Upper Ebro Basin, Spain). Quaternary International, 214: 82-97. doi:10.1016/j.quaint.2009.10.022.

Polo-Díaz, A. (2009): Evidence of successive stabling episodes during Neolithic by microstratigraphy and micromorphology: the rockshelter of Los Husos II (Upper Ebro Basin, Spain). Frankfurter geowiss. Arbelten, 30: 95-105.

Rodríguez González, G. (1979): La Cueva del Nacimiento (Pontones, Jaén). Saguntum, 14: 33-38

Rodríguez González, G. (1997): Últimos cazadores y neolitización del Alto Segura. II Congreso de Arqueología Peninsular. Celebrado en Zamora, del 24 al 27 de Septiembre de 1996. Vol. 1 (P. Bueno Ramírez, R. Balbín Berhmann, eds.), Fundación Rei Alfonso Enriques, Zamora: 405-414.

Rodríguez GonzÁlez, D. (2008): Los primeros agricultores de Castilla-La Mancha. El neolítico de la Meseta sur. Cueva de Montesinos, Ciudad Real.

Vega Toscano, L. G. (1993): Excavaciones en el Abrigo del Molino del Vadico (Yeste, Albacete). El final del Paleolítico y nos inicios del neolítico en la Sierra Alta del Segura. Jornadas de Arqueología Albacetense en la Universidad Autónoma de Madrid (J. Blánquez Pérez, R. Sanz Gamo, M. T. Musat Hervés, eds.), Junta de Comunidades de Castilla-La Mancha, Madrid: 17-32.

Verdasco, C. (2001): Depósitos naturales de cueva alterados: estudio microsedimentológico de acumulaciones producidas en el neolítico valenciano por la estabulación de ovi-cápridos. Cuaternario y Geomorfología, 15: 85-94.

VERDASCO, C. (2002): Man: agent of accumulation and alteration of natural deposits. Quaternary International, 93-94: 215-220. doi:10.1016/S1040-6182(02)00020-4. 